\title{
Convergência dos sistemas financeiros no período 1971-2000: uma análise por meio de Matrizes de Markov
}

Nilton Clóvis Machado de Araújo Professor da Pontifícia Universidade Católica do Rio Grande do Sul Valter José Stulp Professor da Pontifícia Universidade Católica do Rio Grande do Sul

\section{Palavras-chave}

sistemas financeiros, convergência,

Matrizes de Markov.

Classificação JEL G10, G21

Key words

financial systems, convergence,

Markov matrices.

JEL Classification G10, G21

\section{Resumo}

Este artigo faz uma análise de convergência dos sistemas financeiros de 27 países, em diferentes graus de desenvolvimento, nos períodos 1971-1990 e 1990-2000, a partir de dois indicadores de desenvolvimento financeiro relacionados com o papel dos intermediários financeiros bancários nesses sistemas, as relações crédito/PIB e depósitos/PIB. A análise de convergência foi realizada através da metodologia de Matrizes de Markov. Os resultados obtidos a partir de dados dos dois períodos indicam não haver convergência dos sistemas financeiros para um padrão único no longo prazo. Verifica-se também que o padrão de convergência se altera no segundo período, caracterizado pelo aprofundamento do processo de globalização financeira, que produziu grandes mudanças nos mercados financeiros da maioria dos países. No período 1990-2000, os resultados obtidos sugerem tendência de convergência para duas classes extremas no que diz respeito ao papel dos bancos nos sistemas financeiros dos países estudados.

\section{Abstract}

This article analyzes the convergence of the financial systems of 27 developed and underdeveloped countries, based on their performance during the periods from 1971 to 1990, and 1990 to 2000. The analysis was performed using Markov matrices, and was based on two variables related to the role of financial intermediaries in these systems: credit/GDP ratio and volume of deposits/GDP ratio. The results obtained, based on the data for these two periods, indicate that there will not be convergence of the financial systems of these countries into a single pattern over the long term. The pattern of convergence based on the 1990-2000 period differs from the pattern based on the first period. The second period was characterized by the intensification of financial globalization, which resulted in great changes in the financial markets of many countries.

The results from this period suggest a tendency to converge towards two extremes with respect to the function of the banks in financial systems. 


\section{1_Introdução}

As evidências mostram que os sistemas financeiros dos diferentes países apresentam características distintas. Uma distinção geralmente aceita é a entre sistemas financeiros orientados para bancos e sistemas financeiros orientados para mercados, diversidade adotada de acordo com as formas predominantes de financiamento e controle das grandes empresas não-financeiras nos diferentes países. Nos sistemas financeiros orientados para mercados, que seriam basicamente o caso dos Estados Unidos e o da GrãBretanha, as empresas tenderiam a recorrer mais aos mercados de capitais na busca de recursos financeiros, e esses mercados constituir-se-iam nos principais mecanismos de controle dos seus administradores. Nos sistemas orientados para bancos, sendo geralmente apontados como exemplos os casos do Japão e da Alemanha, esse papel seria assumido principalmente pelos bancos, com os quais as grandes empresas seriam propensas a manter relações duradouras. A esses sistemas pode-se acrescentar os casos dos países em desenvolvimento, em muitos dos quais o Estado assumiu uma forte presença nos mercados financeiros no período pós-II Guerra, como parte de políticas voltadas para o desenvolvimento econômico.
A partir dos anos oitenta, o aprofundamento do processo de globalização, as inovações financeiras e as mudanças na regulamentação dos mercados financeiros poderiam estar contribuindo para conduzir a uma padronização dos sistemas financeiros dos países desenvolvidos. Outros fatores que poderiam estar contribuindo para a convergência dos sistemas financeiros seriam a maior integração dos mercados financeiros dos países em desenvolvimento com os mercados internacionais e a redução da participação direta do estado nesses mercados, que foram iniciados nos anos oitenta e intensificados nos anos noventa. Por outro lado, estudos recentes que têm analisado a questão da convergência dos sistemas financeiros constataram que eles continuam apresentando características peculiares nos diferentes países, sugerindo a existência de path dependence na evolução desses sistemas.

Este trabalho busca, através do uso de dois indicadores diretamente relacionados com o papel dos bancos nos sistemas financeiros (as relações crédito/PIB e depósitos/PIB), analisar a hipótese de convergência dos mercados financeiros, a partir dos dados de 27 países, incluindo países desenvolvidos com sistemas financeiros orientados para os mercados, países desenvolvidos com sistemas financeiros orientados para bancos e 

Podem ser destacadas aqui as contribuições dos trabalhos que assumem a existência de assimetrias de informação nos mercados financeiros. Nessa linha, podem-se destacar como contribuições importantes para um melhor entendimento dos mercados financeiros os trabalhos sobre contratos financeiros ótimos (Dowd, 1992), a literatura sobre o papel dos intermediários financeiros (Bhattacharya e Thakor, 1993) e os modelos que analisam os efeitos de imperfeições de informação nos mercados acionários e de crédito (Stiglitz e Weiss, 1981). países em desenvolvimento, no período 1971-2000. A análise da convergência foi realizada através da metodologia de Matrizes de Markov. Essa metodologia utiliza uma matriz de probabilidades de transição dos países de uma classe de crédito/PIB ou de depósitos/PIB para outra classe, do início para o final de cada período considerado.

\section{2_ Diferentes tipos de sistema financeiro e convergência}

Autores como Schumpeter (1982) e Gurley e Shaw (1955) destacaram o papel dos mercados financeiros, em particular dos bancos, no processo de desenvolvimento econômico. Isso também foi tratado por Gerschenkron (1962), em seus estudos históricos sobre os processos de industrialização dos países de industrialização tardia. No período recente, tem-se verificado um grande desenvolvimento de trabalhos voltados para uma melhor compreensão teórica dos mercados financeiros, tanto em nível microeconômico quanto macroeconômico. ${ }^{1}$ Paralelamente a isso, nas últimas décadas tem surgido um grande volume de evidências empíricas quanto ao papel dos mercados financeiros no desenvolvimento econômico, em especial a partir dos trabalhos de King e Levine (1993). Esses autores verificaram que o grau de desenvolvimento financeiro explica de forma significativa o grau de desenvolvimento de um país, evidência que contraria o papel passivo atribuído a esses mercados por parte da teoria econômica tradicional.

Outra vertente da literatura econômica tem-se voltado para a análise dos diferentes tipos de sistema financeiro existentes nos países desenvolvidos. Uma tipologia geralmente aceita é a que separa os sistemas financeiros em sistemas orientados para bancos e sistemas orientados para mercados, classificação baseada no papel que os diferentes segmentos do setor financeiro desempenham no financiamento e no controle das grandes empresas (Rybckzinski, 1984). O que caracterizaria os sistemas orientados para bancos seria o papel assumido por essas instituições no financiamento e no controle das empresas. Nesses sistemas, as empresas obteriam recursos externos para financiamento basicamente através dos bancos, que, por sua vez, seriam os principais encarregados do monitoramento dos administradores, mediante participações acionárias diretas e/ou como monitores delegados por outros acionistas. Além disso, a propriedade das ações das empresas seria mais concentrada, com 
uma maior participação acionária dos bancos. Nos sistemas orientados para esse tipo de instituição, os mercados de capitais seriam relativamente fracos e existiriam relações de longo prazo entre bancos e grandes empresas não-financeiras. Além disso, a regulamentação dos sistemas financeiros nesses sistemas seria mais tolerante em relação à participação dos bancos no controle de empresas não-financeiras. Como exemplos de sistemas financeiros orientados para bancos, são geralmente apontados os países de industrialização tardia, em especial os casos da Alemanha e do Japão. Em menor escala, também são citados outros países da Europa continental, como a França e a Itália.

Nos sistemas financeiros orientados para os mercados, os mercados de capitais teriam peso maior como fonte de recursos para as empresas, com os bancos desempenhando um papel secundário. Nesses sistemas, o papel dos bancos comerciais restringir-se-ia aos empréstimos de curto prazo, sendo os recursos gerados internamente e os captados nos mercados de capitais as fontes mais importantes para investimento das empresas. Além disso, nesses sistemas a propriedade das ações seria mais pulverizada do que nos sistemas orientados para bancos, e os mercados de capitais desempenhariam o papel de controle sobre os ad- ministradores das empresas. Como exemplos de sistemas orientados para mercados, são geralmente citados os EUA e a Grã-Bretanha. ${ }^{2}$ Nos EUA, um fator importante para explicar a baixa interferência dos bancos nas empresas foi a regulamentação do setor financeiro, que muito cedo impôs a separação entre as atividades financeiras de curto prazo e as de longo prazo, cabendo as primeiras aos bancos comerciais e as segundas aos mercados de capitais. ${ }^{3}$

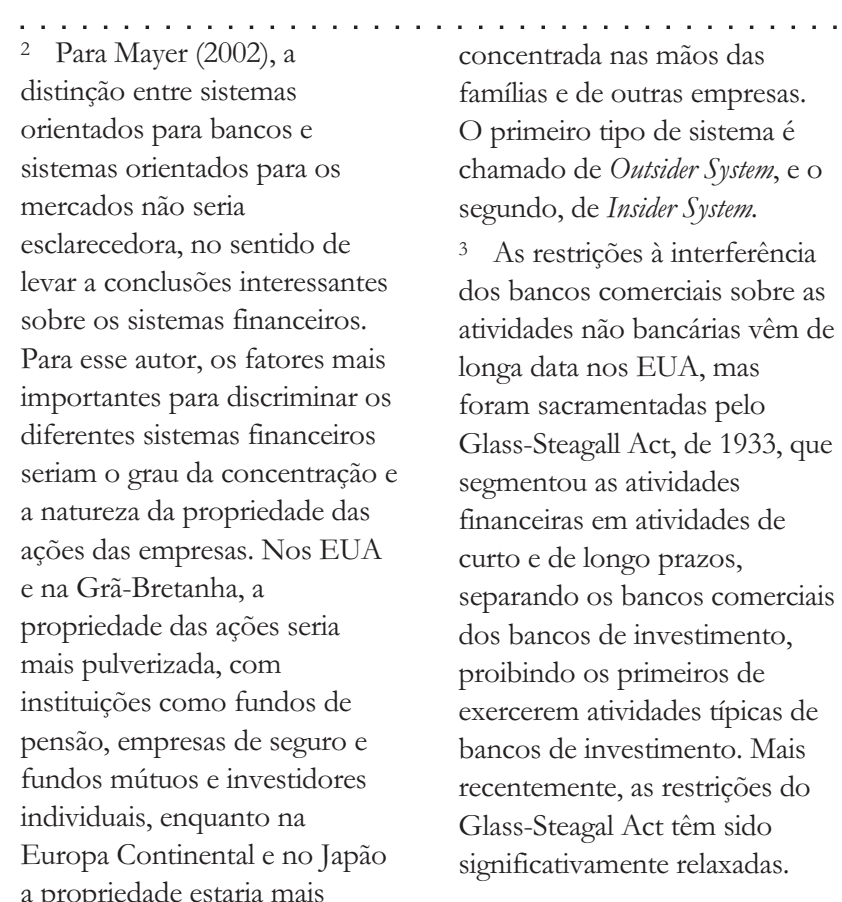


Nos países em desenvolvimento, o Estado assumiu papel de liderança nos mercados financeiros no período pós-II Guerra, através de instituições como bancos de desenvolvimento e, em certos casos, através da estatização de todo o sistema financeiro, como ocorreu na Coréia do Sul nos anos sessenta. Essas medidas estiveram associadas a políticas de desenvolvimento econômico rápido e foram adotadas valendo-se de diagnósticos quanto à insuficiência de poupança interna e à existência de falhas nos mercados financeiros privados. Em muitos desses países, adotou-se algum tipo de arranjo institucional que envolvia o Estado e o setor privado, visando suprir as deficiências do sistema financeiro privado. Esses arranjos, chamados por alguns autores de "mercados de capitais quase-internos" (Cho e Hellmann, 1993; Araújo, 1997), a partir da noção de mercados de capitais internos, utilizada por Williamson (1989) para analisar os conglomerados de estrutura $\mathrm{M}$, podem ser vistos como alternativas ao papel assumido pelos bancos nos países de industrialização tardia, na mobilização de poupança e sua alocação em grandes investimentos considerados necessários para promover o desenvolvimento das economias desses países.

As alterações ocorridas nos mercados financeiros a partir dos anos oiten- ta, como o aumento da mobilidade do capital financeiro entre países, o processo de integração européia, a tendência de desregulamentação e a abertura dos mercados financeiros dos países em desenvolvimento, têm produzido efeitos sobre os sistemas financeiros que podem ter estimulado a convergência dos diferentes sistemas para um padrão único. Essas mudanças, em grande parte associadas ao chamado "processo de globalização financeira", tem sido caracterizadas pelo crescimento dos investidores institucionais nos mercados financeiros, pelas tendências de desintermediação e de securitização nesses mercados, estimuladas pelas inovações financeiras. As tendências de desintermediação financeira e de securitização, com forte crescimento na maioria dos países desenvolvidos nas últimas décadas, podem ter contribuído para o aumento da importância dos mercados de capitais, em detrimento dos intermediários financeiros. Além disso, no segmento de intermediação financeira, teria ocorrido a perda de importância dos bancos e o crescimento dos intermediários financeiros não bancários, como fundos de pensão e seguros. À primeira vista, os efeitos desse processo parecem indicar uma tendência de padronização dos mercados financeiros em nível internacional, no sentido de sistemas financeiros mais 
orientados para os mercados. No entanto, Bianco, Gerali e Massaro (1997) constataram que, apesar de ter se verificado uma certa convergência dos sistemas financeiros dos países desenvolvidos no período recente, algumas diferenças básicas permanecem. Esses autores mostraram que, embora em alguns países como França e Itália tenham se verificado mudanças no sentido de uma maior orientação para os mercados, em outros, como nos casos da Alemanha e do Japão, a orientação para os bancos se mantém. Resultados semelhantes foram obtidos por Schmidt, Hackethal e Tyrell (1999), em estudo que analisa os efeitos da desintermediação sobre o papel dos bancos na Alemanha, na França e na Grã-Bretanha. Esses autores contataram que, exceto no caso da França, não se verificou um aumento da participação dos mercados em detrimento do segmento de intermediação financeira. No entanto, dentro do segmento de intermediação, esses autores constataram o crescimento dos intermediários financeiros não bancários, em prejuízo dos bancos. Como explicação teórica para as evidências quanto à permanência de sistemas financeiros com características distintas, Bianco, Gerali e Massaro (1997) sugerem a existência de path dependence nos sistemas financeiros, com a existência de equilíbrios múltiplos; dife- rentes tipos de sistema financeiro seriam capazes de conduzir a níveis semelhantes de desenvolvimento econômico.

Nos países em desenvolvimento, por outro lado, em especial a partir do final dos anos oitenta, os processos de abertura financeira, com maior integração aos mercados internacionais, e de redução da presença direta do Estado têm contribuído para a ocorrência de mudanças significativas nos sistemas financeiros. Em muitos desses países, essas mudanças contribuíram para a modernização e o aprofundamento dos mercados financeiros, através da aceleração da absorção das inovações financeiras e de outras práticas adotadas nos países desenvolvidos. Além disso, deve-se destacar que a abertura dos mercados financeiros foi em muitos casos acompanhada de mudanças em muitos aspectos da regulamentação desses mercados, que ocorreram no sentido de proporcionar um ambiente institucional homogêneo para as transações financeiras em nível internacional. Como exemplos, podem ser citados os casos dos chamados "mercados emergentes", ou seja, países em desenvolvimento que atraíram grandes fluxos de capital estrangeiro para seus mercados financeiros durante a década de noventa, como os casos dos países do Leste da Ásia, Brasil, Argentina e México. 
As mudanças ocorridas nos sistemas financeiros durante as últimas décadas mostram a importância de se buscar evidências empíricas sobre o problema da convergência entre os sistemas financeiros dos diferentes países no período recente. Para a análise da convergência proposta neste trabalho, foram utilizados dois indicadores de desenvolvimento financeiro relacionados com o papel dos intermediários financeiros bancários nesses sistemas, as relações crédito/PIB e depósitos/PIB. Esses indicadores, embora não consigam captar de forma plena as mudanças que vêm ocorrendo nos sistemas financeiros, em particular no sentido de enquadrá-los na tipologia mencionada anteriormente, refletem alguns dos movimentos importantes ocorridos nos mercados financeiros nas últimas décadas, em especial as tendências de desintermediação financeira e de crescente securitização nos mercados financeiros, que poderiam estar contribuindo para a redução do papel dos bancos nos sistemas financeiros. ${ }^{4}$

Para tentar captar os efeitos das mudanças no sentido da convergência dos sistemas financeiros, foram escolhidos 27 países, incluindo países desenvolvidos com sistemas financeiros orientados para bancos, países desenvolvidos com sistemas financeiros orientados para os mercados e países em desenvolvimento, com destaque para os chamados "mercados emergentes". O número de países escolhido foi tal que permitisse incluir a totalidade dos países desenvolvidos, alguns países da Europa com grau intermediário de desenvolvimento e os principais países em desenvolvimento, de forma a se ter um número de observações que permitisse a aplicação da metodologia utilizada (Matrizes de Markov). Além disso, o número de países analisados foi restringido pelas limitações quanto à disponibilidade de dados sobre os indicadores utilizados. Não foram incluídos no trabalho os países do Leste Europeu pelo fato destas economias estarem em fase de transição, de economias centralizadas para economias capitalistas, durante o período estudado. $\mathrm{O}$ fato de não estarem sob condições de livre mercado durante parte do período analisado comprometeria os resultados obtidos.

Os períodos analisados foram 1971-1990 e 1990-2000. A separação em dois períodos foi feita para possibilitar a visualização dos efeitos do aprofundamento do processo de globalização financeira, ocorrido nos anos noventa, sobre o padrão de convergência dos indicadores financeiros estudados. Para a 
análise dos dados, foi utilizada a matriz de probabilidades de transição dos países de um nível de cada variável para outro, denominada de "Matriz de Markov". Os dados foram obtidos na publicação International Financial Statistics Yearbook do Fundo Monetário Internacional para os anos estudados.

\section{3_Metodologia}

Este trabalho analisa a convergência de um conjunto de 27 países em termos de volume de crédito/PIB e de volume de depósitos/PIB nos períodos de 1971 a 1990 e de 1990 a 2000. As relações crédito/PIB e depósitos/PIB dos 27 países estudados podem ser vistas na Tabela 1.1, do Anexo A. A análise da convergência foi realizada através da metodologia de Matrizes de Markov. Esta metodologia utiliza uma matriz de probabilidades de transição dos países de uma classe de crédito/PIB ou de depósitos/PIB para outra classe, do início para o final de cada período considerado.

Para a determinação das Matrizes de Markov, expressou-se, inicialmente, o valor de cada variável, crédito/PIB e depósitos/PIB, de cada país, em relação à média do conjunto dos 27 países que foi considerada como sendo igual a 1,00 .
Esse procedimento foi adotado para cada um dos três anos, 1971, 1990 e 2000. Os dados foram retirados do International Financial Statistics Yearbook (IFSY), publicado pelo FMI, dos anos estudados. O crédito refere-se ao crédito doméstico do setor bancário (linha 32 do IFSY), e os depósitos, à soma dos depósitos à vista mais depósitos a prazo e poupança nas instituições bancárias (linhas 24 e 25 do IFSY).

Obteve-se, assim, uma função de distribuição para cada variável, em relação a cada um dos três anos considerados. Isso possibilitou a separação dos países em classes de crédito/PIB e classes de depósitos/PIB. Com isso, é possível verificar, em relação a cada variável, como os países migraram de uma classe para outra entre o ano inicial e o final de cada período considerado. Esta informação origina a matriz de probabilidades de transição dos países entre classes, denominada, como já dito, "Matriz de Markov".

Nesse procedimento há duas decisões a ser tomadas, o ponto inicial dos intervalos de classe e a dimensão de cada intervalo de classe. Como cada distribuição tem por referência a média dos 27 países, considerada como igual à unidade, é esse o ponto de referência ou inicial dos intervalos de classe. 
A dimensão do intervalo de classe é importante para a estimativa da função densidade de probabilidade de cada distribuição. Um intervalo muito grande faz com que haja um grande número de pontos em cada classe, diminuindo a variância da estimativa. No entanto, isso leva a um formato de histograma menos adequado, pois aumenta o viés da estimativa. Com um intervalo pequeno, ocorre o contrário: reduz-se o viés, mas aumenta a variância (Pagan e Ullah, 1999).

A função densidade de probabilidade de cada variável, em relação a cada um dos três anos, pode ser estimada como:

$\hat{f}(x)=\frac{1}{n h} \sum_{i=1}^{n} I\left(x-\frac{b}{2} \leq x_{i} \leq x+\frac{b}{2}\right)$

em que $I\left(x-\frac{b}{2} \leq x_{i} \leq x+\frac{b}{2}\right)$ será igual a 1 se $x_{i}$ se encontrar no intervalo $(x-h / 2$, $x+b / 2)$ e será igual a zero em caso contrário (Pagan e Ullah, 1999). A função $\hat{f}(x)$ é a freqüência relativa por unidade no intervalo $(x-h / 2, x+h / 2)$. Ela é a ordenada do histograma no ponto $x$. Cada ponto $x$ representa o centro de um intervalo. O $n$ é igual a 27 , ou seja, o número total de observações que são os países incluídos no estudo.

O valor de $h$ deve ser escolhido de modo a resultar em um trade-off ótimo entre viés e variância da estimativa. Esse valor é encontrado através do procedi- mento sugerido por Devroye e Györfi (1985, apud Magrini 1999, p. 264), que minimizam a integral do erro absoluto (IAE), dada por:

$L A E=\int_{-\infty}^{\infty}|\hat{f}(x)-f(x)| d x$

Com base nesse procedimento, aqueles autores concluem que, quando a distribuição é normal, o valor ótimo do intervalo de classe é dado por:

$h=2,72 s n^{-1 / 3}$

Nessa expressão, s é o desvio-padrão da distribuição, e $n$, o número de observações.

Assim, procedeu-se, inicialmente, ao teste de normalidade de cada distribuição, através do teste de KolmogorovSmirnov. Para este teste, comparou-se a distribuição de freqüência acumulada observada com a acumulada teórica esperada na hipótese de normalidade. O valor absoluto da diferença máxima entre as duas constitui o valor $D$ para o teste de Kolmogorov-Smirnov (Siegel, 1956).

Estabelecidas as classes de níveis de crédito/PIB e de depósitos/PIB, determinaram-se quantos países migraram de uma classe para outra, ou permaneceram na mesma, entre os anos de 1971 e 1990 e também entre 1990 e 2000. Esta informação originou as matrizes de pro- 
babilidades de transição, ou Matrizes de Markov. Essas resultaram em sistemas de equações de diferenças, cujas soluções informam sobre os processos de convergência, ou não, do crédito/PIB e dos depósitos/PIB entre os países e a velocidade dessa convergência.

\section{4_Resultados}

\section{1_Os sistemas de equações de diferenças e suas soluções}

Os valores de $D$ obtidos através do teste de normalidade de Kolmogorov-Smirnov, para a variável crédito/PIB, em relação aos anos 1971, 1990 e 2000 são, respectivamente, iguais a 0,204, 0,026 e 0,056 . O valor limite do teste a $5 \%$, para 27 observações, é igual 0,258 (ver Tabela E, p. 251 em Siegel, 1956). Como os valores obtidos são inferiores a esse valor limite, não se rejeita a hipótese de normalidade ao nível de significância estatística de $5 \%$ em relação a cada uma dessas três distribuições.

Do mesmo modo, os valores de $D$ obtidos para a variável depósitos/PIB nos anos 1971, 1990 e 2000 são, respectivamente, 0,093, 0,056 e 0,064. Portanto, em relação a essa variável também não se rejeita a hipótese de normalidade para cada uma das três distribuições ao nível de significância de 5\%.
$\mathrm{Na}$ estimativa de $h$, através da expressão (3), para a variável crédito/PIB, obtiveram-se os valores de $0,4321,0,3676$ e 0,4056 , respectivamente, para os anos 1971, 1990 e 2000. Optou-se pelo valor médio de 0,4018 para definir intervalos de classe idênticos para as distribuições dessa variável nos três anos considerados (ver Tabela 2.1, do Anexo B). Esse método para a obtenção de $b$ é o mesmo utilizado por autores como Magrini (1999) e Le Gallo (2001).

Assim, foram estabelecidas quatro classes de níveis de crédito/PIB:

a. valores abaixo de 0,5982 ;

b. valores entre 0,5982 e 1,00;

c. valores acima de 1,00 até 1,4018;

d. valores acima de 1,4018.

Não se procedeu a uma subdivisão da classe abaixo de 0,5982, nem da classe acima de 1,4018 , por causa do pequeno número de observações que seriam incluídas nas classes extremas.

$\mathrm{Na}$ estimativa de $h$ para a variável depósitos/PIB, obtiveram-se os valores de $0,4537,0,3953$ e 0,4116 para os anos 1971, 1990 e 2000, respectivamente. A opção foi pelo valor médio de 0,4202 para determinar intervalos de classe idênticos para as distribuições da variável nos três anos (ver Tabela 2.2, do Anexo B).

Portanto, foram estabelecidas quatro classes de níveis de depósitos/PIB: 
a. valores abaixo de 0,5798;

b. valores entre 0,5798 e 1,00;

c. valores acima de 1,00 e 1,4202;

d. valores acima de 1,4202.

Pelo mesmo motivo mencionado em relação à outra variável, não foi realizada uma subdivisão da classe situada abaixo de 0,5798 e nem da classe acima de 1,4202.

Com base nas classes de níveis de crédito/PIB e de depósitos/PIB em cada um dos três anos considerados (Tabelas 2.1 e 2.2, do Anexo B), determinaram-se as matrizes de probabilidades de transição dos países de uma classe para outra, denominadas "Matrizes de Markov". Essas constituem a base para os sistemas de equações de diferenças. Sendo $F_{t}$ a distribuição da variável no tempo $t$, e utilizando-se a matriz de transição de Markov, determinou-se o sistema de equações que expressa a evolução da distribuição ao longo do tempo. Esse sistema é representado por:
$F_{t+1}=M F_{t}$

em que $M$ é a matriz de transição de Markov, indicando a probabilidade de cada país na classe $i$ de crédito/PIB ou depósitos/PIB, no tempo $t$, estar na classe $j$ no tempo $t+1$. Esse procedimento tem por base o princípio de que as probabilidades de transição sejam estacionárias, isto é, que a probabilidade de passagem de uma classe para outra seja invariável no tempo.

Analisou-se a evolução dos países quanto ao crédito/PIB e aos depósitos/ PIB com base em dois períodos de tempo, de 1971 a 1990 e de 1990 a 2000. Para essa finalidade, foram constituídos quatro sistemas de equações de diferenças, dois para cada variável, sendo um para cada período. As equações e as respectivas matrizes de transição podem ser vistas no Anexo $\mathrm{C}$ deste trabalho. As soluções dos quatro sistemas de equações de diferenças estão apresentadas nas Figuras 1 a 4 (Simon e Blume, 1994, cap. 23).

\section{Figura 1_ Solução do sistema de equações de diferenças que descreve a evolução dos países quanto ao volume de crédito/PIB (Período base: 1971 a 1990)}

$$
\left[\begin{array}{l}
E_{1 t} \\
E_{2 t} \\
E_{3 t} \\
E_{4 t}
\end{array}\right]=1\left[\begin{array}{l}
0,249 \\
0,469 \\
0,219 \\
0,063
\end{array}\right](1)^{t}+0,181\left[\begin{array}{r}
-0,869 \\
0,397 \\
0,332 \\
0,141
\end{array}\right](0,689)^{t}+0,174\left[\begin{array}{r}
0,467 \\
-1,206 \\
-0,125 \\
0,864
\end{array}\right](0,406)^{t}-0,291\left[\begin{array}{r}
0,086 \\
-0,770 \\
0,630 \\
0,055
\end{array}\right](-0,446)^{t}
$$


Figura 2_Solução do sistema de equações de diferenças que descreve a evolução dos países quanto ao volume de crédito/PIB (Período base: 1990 a 2000)

$$
\left[\begin{array}{l}
E_{1 t} \\
E_{2 t} \\
E_{3 t} \\
E_{4 t}
\end{array}\right]=1\left[\begin{array}{l}
0,322 \\
0,158 \\
0,264 \\
0,257
\end{array}\right](1)^{t}+0,029\left[\begin{array}{r}
-0,923 \\
-0,148 \\
0,460 \\
0,610
\end{array}\right](0,780)^{t}-0,231\left[\begin{array}{r}
0,348 \\
-0,203 \\
-0,561 \\
0,461
\end{array}\right](0,492)^{t}-0,156\left[\begin{array}{r}
-0,185 \\
0,854 \\
-0,472 \\
-0,198
\end{array}\right](0,056)^{t}
$$

Figura 3_Solução do sistema de equações de diferenças que descreve a evolução dos países quanto ao volume de depósitos/PIB (Período base: 1971 a 1990)

$$
\left[\begin{array}{l}
E_{1 t} \\
E_{2 t} \\
E_{3 t} \\
E_{4 t}
\end{array}\right]=1\left[\begin{array}{l}
0,067 \\
0,335 \\
0,424 \\
0,174
\end{array}\right](1)^{t}+0,160\left[\begin{array}{r}
0,812 \\
0,166 \\
-0,468 \\
-0,511
\end{array}\right](0,520)^{t}-0,131\left[\begin{array}{r}
0,319 \\
-0,836 \\
-0,108 \\
0,625
\end{array}\right](0,238)^{t}-0,191\left[\begin{array}{r}
0,085 \\
-0,618 \\
0,592 \\
0,059
\end{array}\right](-0,225)^{t}
$$

Figura 4_Solução do sistema de equações de diferenças que descreve a evolução dos países quanto ao volume de depósitos/PIB (Período base: 1990 a 2000)

$$
\left[\begin{array}{l}
E_{1 t} \\
E_{2 t} \\
E_{3 t} \\
E_{4 t}
\end{array}\right]=0,464\left[\begin{array}{l}
1 \\
0 \\
0 \\
0
\end{array}\right](1)^{t}+0,536\left[\begin{array}{l}
0 \\
0 \\
0 \\
1
\end{array}\right](1)^{t}-0,495\left[\begin{array}{r}
0,664 \\
-0,796 \\
-0,613 \\
0,745
\end{array}\right](0,850)^{t}-0,143\left[\begin{array}{r}
0,087 \\
0,683 \\
-0,731 \\
0,135
\end{array}\right](0,013)^{t}
$$

A Figura 1 indica que, no longo prazo, ao manter-se a tendência observada no período de 1971 a 1990, quanto ao volume de crédito/PIB aplicado pelos países, 24,9\% deles situar-se-ão na classe
$1,46,9 \%$ estarão na classe $2,21,9 \%$ na de número 3 e apenas $6,3 \%$ na classe 4 .

A segunda raiz característica do sistema de equações, em valor absoluto, fornece uma medida da velocidade com 
que o equilíbrio de longo prazo é alcançado. Ela permite estimar o tempo necessário para percorrer a metade da distância entre a posição inicial e a de equilíbrio de longo prazo $(d m)$. Essa informação corresponde a:

$$
\begin{aligned}
d m & =-\frac{\log 2}{\log \left|r_{2}\right|}= \\
& =-\frac{\log 2}{\log |0,689|}=1,86 \text { períodos }
\end{aligned}
$$

Como o período corresponde a 19 anos (de 1971 a 1990), tem-se que esse tempo, expresso em número de anos, é igual a $1,86 \times 19=35$ anos.

A Figura 2 indica que, no longo prazo, ao manter-se a tendência observada no período de 1990 a 2000, quanto ao volume de crédito/PIB aplicado pelos países, 32,2\% deles situar-se-ão na classe $1,15,8 \%$ estarão na classe $2,26,4 \%$ na de número 3 e $25,7 \%$ na classe 4 .

O tempo necessário para o sistema percorrer a metade da distância entre a posição inicial e a de equilíbrio de longo prazo é igual a:

$$
\begin{aligned}
d m & =-\frac{\log 2}{\log \left|r_{2}\right|}= \\
& =-\frac{\log 2}{\log |0,780|}=2,79 \text { períodos }
\end{aligned}
$$

Como o período corresponde a 10 anos (de 1990 a 2000), tem-se que esse tempo, expresso em número de anos, é igual a $2,79 \times 10=28$ anos.

A Figura 3 indica que, no longo prazo, ao manter-se a tendência observada no período de 1971 a 1990, quanto ao volume de depósitos/PIB existentes nos países, 6,7\% deles situar-se-ão na classe $1,33,5 \%$ estarão na classe $2,42,4 \%$ na de número 3 e $17,4 \%$ na classe 4 .

O tempo necessário para o sistema percorrer a metade da distância entre a posição inicial e a de equilíbrio de longo prazo é igual a:

$$
\begin{aligned}
d m & =-\frac{\log 2}{\log \left|r_{2}\right|}= \\
& =-\frac{\log 2}{\log |0,520|}=1,06 \text { períodos }
\end{aligned}
$$

Como o período corresponde a 19 anos (de 1971 a 1990), tem-se que esse tempo, expresso em número de anos, é igual a 1,06 x $19=20$ anos.

A Figura 4 indica que, no longo prazo, ao manter-se a tendência observada no período de 1990 a 2000, quanto ao volume de depósitos monetários/PIB existentes nos países, 46,4\% deles situar-se-ão na classe 1 e 53,6\% na classe 4 . Não haverá nenhum país na classe 2 (e) nem na 3 . 
O tempo necessário para o sistema percorrer a metade da distância entre a posição inicial e a de equilíbrio de longo prazo é igual a:

$$
\begin{aligned}
d m & =-\frac{\log 2}{\log \left|r_{2}\right|}= \\
& =-\frac{\log 2}{\log |0,850|}=4,27 \text { períodos }
\end{aligned}
$$

Como o período corresponde a 10 anos (de 1990 a 2000), tem-se que esse tempo, expresso em número de anos, é igual a $4,27 \times 10=42,7$ anos.

\section{2_Análise dos resultados}

\subsection{1_O período 1971-1990}

A análise do primeiro indicador parte de quatro classes iniciais, sendo a primeira composta basicamente de países em desenvolvimento com baixa relação crédito/ PIB, a segunda de países em desenvolvimento e desenvolvidos com média-baixa relação crédito/PIB, a terceira formada por Portugal e África do Sul, que apresentam média-alta relação crédito/PIB, e de uma quarta classe, formada por países desenvolvidos com alta relação crédito/ PIB (Tabela 2.1, do Anexo B). A maioria dos países desenvolvidos apresentava relações crédito/PIB nas faixas média-baixa e média-alta em 1971, incluindo os ca- sos da Grã-Bretanha e da França. Com relações crédito/PIB altas no início do período aparecem os EUA, a Itália, a Alemanha e o Japão, os dois últimos classificados como sistemas orientados para bancos. A grande maioria dos países em desenvolvimento apresentava relações crédito/PIB baixas em 1971, com as exceções do México, da Venezuela e da África do Sul, que se situaram na classe média-baixa. No final do período, os EUA e a Itália haviam caído para a classe média-alta, a Grã-Bretanha e a França haviam subido da média-baixa para a alta e média-alta, respectivamente, enquanto a Alemanha e o Japão haviam permanecido com altas relações crédito/PIB. Os países desenvolvidos restantes tenderam a aumentar ou manter estáveis suas relações crédito/PIB no período, o mesmo ocorrendo com os países europeus com grau de desenvolvimento mais baixo, com exceção de Portugal, que caiu para a classe 2 .

Quanto aos países em desenvolvimento, os países da América Latina, com as exceções do Brasil e do Chile, mantiveram-se com relação crédito/PIB baixa, enquanto os países asiáticos aumentaram suas relações no período. As mudanças mostram que os efeitos dos movimentos de securitização e desintermediação sobre o papel dos bancos foram significati- 
vos nos EUA, não se mostrando muito expressivos na maioria dos outros países desenvolvidos, em particular nos países com sistemas financeiros orientados para bancos, como Alemanha e Japão.

A análise de convergência para o período 1971-1990, sintetizada na Tabela 1, mostra que o número inicial de classes foi mantido, havendo crescimento do percentual de países nos grupos 1 e 3 e perda de importância das classes 2 e 4, em relação à situação inicial de 1971 . O período necessário para percorrer metade da distância até o equilíbrio de longo prazo é de 35 anos. Verifica-se também que a maioria dos países $(72 \%)$ tende para uma relação crédito/PIB relativamente baixa (classes 1 e 2), o que pode estar associado aos efeitos do processo de desintermediação financeira, que atingiu muitos países desenvolvidos, especialmente na segunda metade do pe-

Tabela 1_Relação crédito/PIB: percentual de países em cada classe, no período estudado e no equilíbrio de longo prazo

\begin{tabular}{|c|c|c|c|}
\hline Classes & 1971 & 1990 & Equilíbrio LP \\
\hline Classe 1 & 14,8 & 18,5 & 24,9 \\
\hline Classe 2 & 55,6 & 33,3 & 46,9 \\
\hline Classe 3 & 7,4 & 33,3 & 21,9 \\
\hline Classe 4 & 22,2 & 14,8 & 6,3 \\
\hline Total & 100,0 & 100,0 & 100,0 \\
\hline
\end{tabular}

Fonte: Elaboração própria. ríodo. Por outro lado, a soma dos percentuais de países nas duas classes mais altas se mantém praticamente constante, embora a classe com relação crédito/PIB mais alta perca e a média-alta ganhe importância, sugerindo que há uma tendência de manutenção de um grupo de países com relação crédito/PIB elevada no longo prazo.

O indicador depósitos/PIB parte de uma segmentação dos 27 países em quatro classes: na primeira classe estão incluídos, no período inicial, basicamente países em desenvolvimento e alguns países desenvolvidos, com baixa relação depósitos/PIB; uma segunda classe composta por países desenvolvidos e em desenvolvimento com média-baixa relação; uma terceira e uma quarta classes, com relações média-alta e alta, respectivamente, formadas basicamente por países desenvolvidos (Tabela 2.2, do Anexo B). Entre os países desenvolvidos, aparecem com altas relações depósitos/PIB em 1971, o Japão, a Itália e os EUA, o primeiro classificado como sistema financeiro orientado para bancos, e o último como orientado para mercados, enquanto a Alemanha aparece com relação média-alta. Grã-Bretanha e França aparecem na classe 2, com relação depósitos/PIB médiabaixa no início do período. Outros países desenvolvidos da Europa Ocidental, Ca- 
nadá e Austrália aparecem concentrados nas classes 2 e 3, com relações depósitos/ PIB médias. A maioria dos países em desenvolvimento, exceto Coréia do Sul e México, apresenta baixa relação depósitos/PIB no início do período. Entre os países desenvolvidos, os principais movimentos observados ao longo do período 1971-1990 foram a permanência dos países com sistemas financeiros orientados para bancos (Alemanha e Japão) nas classes mais elevadas de depósitos/PIB e a passagem dos EUA e da Itália, da classe 4 para a classe 3. A maioria dos outros países da Europa, do Canadá e da Austrália subiu da classe 2 para a classe 3 ou permanece na classe 3 , com exceção da Holanda, que subiu para a classe 4. Entre os países em desenvolvimento, verifica-se a tendência de permanência na classe com baixa relação depósitos/PIB, com exce- ção dos países do Leste da Ásia e do Chile e da Venezuela na América Latina. Esses movimentos mostram-se consistentes com o observado para a relação crédito/PIB, especialmente quanto à tendência de redução do papel dos bancos com o intermediários financeiros nos EUA e a sua manutenção nos países com sistemas financeiros orientados para os bancos, casos da Alemanha e do Japão.

A análise de convergência a partir dos dados do período 1971-1990, sintetizados na Tabela 2, mostra que a maioria dos países $(76 \%)$ tende para uma relação intermediária, com o esvaziamento da classe 1, com baixa relação depósitos/ PIB, e com a classe 4 mantendo-se relativamente estável. Entre as classes intermediárias, cresceu significativamente o percentual de países na classe com média-alta relação depósitos/PIB.

Tabela 2_Relação depósitos/PIB: percentual de países em cada classe, no período estudado e no equilíbrio de longo prazo

\begin{tabular}{|c|c|c|c|}
\hline Classes & 1971 & 1990 & Equilíbrio de LP \\
\hline Classe 1 & 22,2 & 14,8 & 6,7 \\
\hline Classe 2 & 37,0 & 29,6 & 33,5 \\
\hline Classe 3 & 22,2 & 40,7 & 42,4 \\
\hline Classe 4 & 18,5 & 14,8 & 17,4 \\
\hline Total & 100,0 & 100,0 & 100,0 \\
\hline
\end{tabular}

Fonte: Elaboração própria. 
5 No caso da Grã-Bretanha, cujo sistema financeiro é em geral considerado orientado para mercados, a alta relação crédito/PIB provavelmente está refletindo o grande volume de operações internacionais realizadas pelos bancos. Segundo Bianco, Gerali e Massaro (1997), aproximadamente $50 \%$ dos ativos financeiros dos bancos do Reino Unido consistem em empréstimos para o resto do mundo.
Esses resultados podem estar refletindo o aumento do aprofundamento financeiro no setor bancário em alguns países em desenvolvimento e o processo de desintermediação e securitização nos países desenvolvidos. Nos primeiros, haveria uma tendência de elevação da relação depósitos/PIB, uma vez que seus sistemas bancários relativamente pouco desenvolvidos ainda comportam um crescimento maior em relação ao PIB, ao passo que, nos países desenvolvidos, os processos de desintermediação bancária e de securitização estariam contribuindo para manter a relação da maioria dos países em um patamar intermediário. Apesar disso, alguns países ainda tendem a manter altas relações crédito/PIB no longo prazo.

\subsection{2_O período 1990-2000}

A observação da relação crédito/PIB no período 1990-2000 mostra que a maioria dos países desenvolvidos tendeu a manter suas relações estáveis durante o período (Tabela 2.1, do Anexo B). As exceções mais notáveis foram os EUA, que continuaram a apresentar uma relação crédito/PIB declinante, e a Holanda e a Bélgica, que passaram para a classe mais alta. Alemanha, Japão e Grã-Bretanha se mantiveram com altas relações crédito
/PIB. ${ }^{5}$ Entre os países da América Latina, observa-se a tendência de convergência para a classe com baixa relação crédito/PIB, exceto no caso do Chile, que se mantém na classe 2 , enquanto os países do Leste da Ásia tendem a elevar suas relações crédito/PIB. Os países europeus de mais baixo grau de desenvolvimento, como Portugal, Grécia e Irlanda, também tenderam a elevar suas relações crédito/PIB. Esses movimentos sugerem a continuidade do processo de desintermediação e securitização nos países desenvolvidos, com crescimento da importância dos mercados de capitais, em particular nos EUA, e a manutenção da importância dos bancos nos países com sistemas financeiros orientados para bancos, como Alemanha e Japão. Nos países em desenvolvimento, o aprofundamento da inserção no processo de globalização financeira ocorrido nos anos noventa não parece ter afetado de forma significativa os indicadores estudados, exceto nos casos dos países do Leste da Ásia. A maioria dos outros países desenvolvidos, com exceção dos casos da Holanda e da Bélgica e da Austrália, teve suas relações crédito/PIB estabilizadas ou reduzidas durante o período. 
A análise de convergência da relação crédito/PIB no período 1990-2000, sintetizada na Tabela 3 , mostra tendência de manutenção das quatro classes iniciais no longo prazo, com a classe 1 , com baixa relação, concentrando $32,2 \%$ dos países; a classe 2 , com relação média-baixa, com $15,8 \%$ dos países; a classe 3 , com relação média-alta, englobando $26,4 \%$ dos países, e a classe 4 , com alta relação crédito/PIB, representando $25,7 \%$ dos países.

Comparando-se com o período anterior (1971-1990), verifica-se que aumentou o percentual de países nas classes 1,3 e 4, destacando-se o crescimento da importância da primeira e da última, que somadas passam a representar $58 \%$ dos países, e acentuada redução da importância da classe 2. Verifica-se também que as classes intermediárias passam agora a concentrar a minoria dos países $(42 \%)$, ao contrário do que ocorria no período anterior. A análise de convergência sugere que a tendência no sentido de uma predominância de uma relação crédito/PIB intermediária (mais concentrada nas classes 2 e 3) observada no período anterior se reverteu, verificando-se agora o crescimento das classes extremas (classes 1 e 4) no longo prazo. Verifica-se também que a velocidade da convergência aumentou em relação ao período anterior, caindo de 35 para 20 anos o tempo necessário para percorrer metade da distância até o ponto de equilíbrio de longo prazo. Isso sugere que as forças por trás das mudanças das variáveis se intensificaram em relação ao período anterior.

Tabela 3_ Relação crédito/PIB: percentual de países em cada classe, no período estudado e no equilíbrio de longo prazo

\begin{tabular}{|c|c|c|c|}
\hline Classes & 1990 & 2000 & Equilíbrio de LP \\
\hline Classe 1 & 18,5 & 25,9 & 32,2 \\
\hline Classe 2 & 33,3 & 18,5 & 15,8 \\
\hline Classe 3 & 33,3 & 33,3 & 26,4 \\
\hline Classe 4 & 14,8 & 22,2 & 25,7 \\
\hline Total & 100,0 & 100,0 & 100,0 \\
\hline
\end{tabular}

Fonte: Elaboração própria. 
A observação dos dados sobre a relação depósitos/PIB no período 19902000 mostra que os países desenvolvidos tenderam a manter ou a reduzir suas relações durante o período (Tabela 2.2, do Anexo B). As exceções foram a Alemanha, que passou para a classe 4 , onde se manteve o Japão, outro país com sistema financeiro orientado para bancos, e a Holanda e a Bélgica. Os casos mais notáveis de redução da relação depósitos/ PIB no período foram os EUA e a Itália, dando continuidade ao observado no período anterior. Essas evidências vêm ao encontro do destacado por outros autores a respeito da maior intensidade do processo de desintermediação e securitização nos EUA (Bianco, Gerali e Massaro, 1997), em relação a outros países desenvolvidos. A maioria dos outros países desenvolvidos, com exceção dos casos da Holanda e da Bélgica e da Austrália, teve suas relações estabilizadas ou reduzidas durante o período. Nos casos dos países em desenvolvimento, de forma semelhante ao que ocorre com a relação crédito/PIB, verifica-se a tendência de concentração na classe mais baixa no que diz respeito aos caso dos países da América Latina (exceto no caso do Chile) e elevação ou estabilidade em classes mais altas no caso dos países do Leste da Ásia.
No caso dos países europeus com nível de desenvolvimento mais baixo, não se verifica uma tendência definida; Portugal manteve-se com uma alta relação depósitos/PIB, a Grécia caiu da classe 3 para a classe 2, e a Irlanda passou da classe 2 para a classe 3 durante o período.

A análise de convergência do indicador depósitos/PIB, a partir dos dados do período 1990-2000, sintetizada na Tabela 4 , mostra uma nítida mudança em relação ao observado no período anterior.

No período 1990-2000, diferentemente do período anterior, as classes extremas passam a concentrar a totalidade dos países. Verifica-se também que a velocidade de convergência se reduziu em relação ao período anterior, passando de 28 para 43 o número de anos necessários para cobrir metade do período de convergência. Comparando-se com o observado para a relação crédito/PIB no mesmo período, verifica-se a mesma tendência de crescimento das classes extremas e um relativo esvaziamento das classes intermediárias. No caso da relação depósitos/PIB, as mudanças foram mais dramáticas, sugerindo que os efeitos das mudanças ocorridas nos mercados financeiros nos anos noventa foram mais intensos do lado das operações passivas dos bancos. 
Tabela 4_Relação depósitos/PIB: percentual de países em cada classe, no período estudado e no equilíbrio de longo prazo

\begin{tabular}{|c|c|c|c|}
\hline Classes & 1990 & 2000 & Equilíbrio de LP \\
\hline Classe 1 & 14,8 & 18,5 & 46,4 \\
\hline Classe 2 & 29,6 & 33,3 & 0 \\
\hline Classe 3 & 40,7 & 25,9 & 0 \\
\hline Classe 4 & 14,8 & 22,2 & 53,6 \\
\hline Total & 100,0 & 100,0 & 100,0 \\
\hline
\end{tabular}

Fonte: Elaboração própria.

Finalmente, essas evidências sugerem que o aprofundamento da globalização financeira nos anos noventa estaria contribuindo para separar os países em duas grandes classes, quanto ao papel dos bancos; uma com alto grau de intermediação via bancos e outra com baixo grau. A tendência de esvaziamento das classes intermediárias pode estar refletindo o crescimento elevado do papel dos investidores institucionais e dos intermediários financeiros não bancários que se intensificou na última década. No entanto, os impactos dessas mudanças sobre o setor bancário não estaria atingindo todos os sistemas financeiros da mesma forma, uma vez que um grande número de países tende a permanecer com relações crédito/PIB e depósitos/ PIB elevadas no longo prazo.

\section{5_Conclusões}

Este trabalho buscou analisar a existência de convergência entre os sistemas financeiros de um conjunto de 27 países, incluindo países com diferentes graus de desenvolvimento, nos períodos 1971-1990 e 1990-2000, a partir do comportamento de dois indicadores - as relações crédito/ PIB e depósitos/PIB.

Os resultados obtidos sugerem a não-existência de convergência dos sistemas financeiros dos países estudados para um padrão único no longo prazo, pelo menos no que diz respeito aos dois indicadores analisados. Esses resultados foram verificados nos dois períodos estudados. No entanto, quando são comparados os dois períodos, constata-se que ocorreram mudanças no padrão de convergência na década de noventa, em rela- 
ção ao período 1971-1990. No que se refere à relação crédito/PIB, ao contrário do que se poderia esperar do aprofundamento do processo de globalização financeira, verifica-se uma tendência de convergência para as classes extremas, em detrimento das classes intermediárias. No caso da relação depósitos/PIB, o comportamento é semelhante, embora nesse caso o esvaziamento das classes intermediárias seja completo. Esses resultados sugerem que as forças que têm atuado sobre os sistemas financeiros dos diferentes países na última década têm agido no sentido de separá-los em dois tipos, quanto à importância do crédito bancário e do papel dessas instituições como captadoras de recursos; sistemas com um nível elevado de intermediação bancária e sistemas com um nível relativamente baixo desse tipo de intermediação. Isso sugere que as tendências de desintermediação e securitização, bem como as outras mudanças que vêm ocorrendo nos sistemas financeiros nas últimas décadas (maior integração dos mercados financeiros, mudanças na regulamentação, etc.), estariam produzindo efeitos diferenciados sobre os setores bancários dos diferentes países.

Essas conclusões vêm ao encontro dos resultados obtidos por Bianco,
Gerali e Massaro (1997), que não encontraram evidências quanto à existência de convergência significativa entre os sistemas financeiros dos países desenvolvidos para um sistema único no período recente. No entanto, os resultados obtidos no presente estudo podem ter sido influenciados, pelo menos em parte, pela presença de países em desenvolvimento no conjunto de países estudados. Em muitos desses países, as mudanças ocorridas no período recente (abertura financeira, redução da presença direta do Estado nos mercados financeiros, crescimento da importância dos mercados de capitais) provavelmente não foram suficientes para caracterizar uma tendência na evolução desses mercados. É provável que, nesses países, devido a seus níveis relativamente baixos de aprofundamento financeiro anteriores aos processos de abertura, as mudanças ocorridas nos sistemas financeiros no período recente tenham tido um efeito diverso do observado nos países desenvolvidos, com sistemas financeiros diversificados e consolidados. Esses fatores contribuiriam para dificultar a visualização de uma tendência definida nos sistemas financeiros do conjunto de países estudado. 


\section{Referências bibliográficas}

ARAÚJO, Nilton C. M. Programas de apoio financeiro do Estado ao setor industrial privado, através do Sistema BNDES, no período pós-1964: uma abordagem através da Economia da Informação. 1997. Tese (Doutorado em Economia) - Universidade Federal do Rio Grande do Sul, Porto Alegre, 1997.

BIANCO, Magda; GERALI, Andréa; MASSARO, Ricardo. Financial Systems Across developed economies: convergence or path dependence? Research in Economics, n. 51, p. 303-331, 1997.

BHATTACHARYA, Sudipto; THAKOR, Anjan V.

Contemporary Banking Theory. Journal of Financial Intermediation, n. 3, p. 2-50, 1993.

CHO, Yoon Je; HELLMANN, T. The government's role in Japanese and Korean credit markets: A Nen Institutional Economics Perspective. World Bank, 1993. (Working Papers, 1190).

DEVROYE, L.; GYÖRFI, L. Nonparametric Density Estimation: the L View. John Wiley, Nova Yorque. 1985.

DOWD, Kevin. Optimal financial contracts. Oxford Economic Papers, n. 44, p. 672-693, 1992.
GERSCHENKRON, Alexander. Economic backwardness in historical perspective: A book of essays. Cambridge, MA, The Belknap Press of Harvard University Press, 1962

GURLEY, John G.; SHAW, E. S. Financial aspects of economic development. The American Economic Review, v. 45, n. 4 , p. 515-538, Sept. 1955

IMF (International Monetary Fund). International Financial Statistics Yearbook 1971, 1990 e 2000.

KING, Robert; LEVINE, Ross. Finance and growth: Schumpeter might be right. Quarterly Journal of Economics, p. 717-737, 1993.

LE GALLO, J. Space-time analysis of GDP disparities among European regions: A Markov chains approach.

Dijon/França: University of Burgundy, mar. 2001.

MAGRINI, S. The evolution of income disparities among the regions of the European Union. Regional Science and Urban Economics, n. 29, 1999.

MAYER, Colin. Financing the new economy: financial institutions and corporate governance. International Economic. and Policy, n. 14, p. 311-326, 2002.
PAGAN, A.; ULLAH, A.

Nonparametric econometrics. Cambridge/UK: Cambridge University Press, 1999 .

RYBCKZINSKI, Tad M. Industrial finance systems in Europe, United States and Japan. Journal of Economic Behavior and Organization, n. 5, p. 275-286, 1984

SCHMIDT, Reinhard H.;

HACKETHAL, Andreas; TYRELL, Marcel.

Desintermediation and the role of banks in Europe: An international comparision. Journal of Financial Intermediation, n. 8, p. 36-67, 1999. SCHUMPETER, J. A. Teoria do desenvolvimento econômico: uma investigação sobre lucros, capital, crédito, juro e o ciclo econômico. São Paulo, Abril Cultural, 1982. (Os Economistas).

SIEGEL, S. Nonparametric statistics for the behavioral sciences. Nova Iorque: McGraw-Hill Book Company, 1956.

SIMON, C. P.; BLUME, L.

Matehematics for economists. Nova Iorque: W.W. Norton \& Company Inc., 1994

STIGLITZ, Joseph E.; WEISS, A. Credit rationing in markets with imperfect information. American Economic Review, v. 73, n. 5, June 1981.
WILLIAMSON, Oliver. Las instituciones económicas del capitalismo. México, Fondo de Cultura Econômica, 1989.

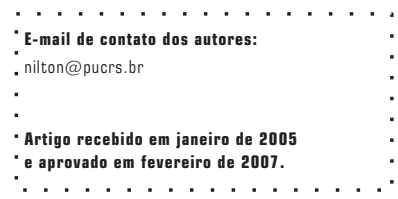


Anexo A

\section{Dados originais das relações Crédito/PIB e Depósitos/PIB}

Tabela 1.1_ Indicadores Crédito/PIB e Depósitos/PIB dos países estudados nos anos 1971, 1990 e 2000

\begin{tabular}{|c|c|c|c|c|c|c|}
\hline \multirow{2}{*}{ Países } & \multicolumn{2}{|c|}{1971} & \multicolumn{2}{|c|}{1990} & \multicolumn{2}{|c|}{2000} \\
\hline & Crédito/PIB & Depósitos/PIB & Crédito/PIB & Depósitos/PIB & Crédito/PIB & Depósitos/PIB \\
\hline Argentina & 0,315385 & 0,15385 & 0,324207 & 0,08266 & 0,343332 & 0,27450 \\
\hline Brasil & 0,387152 & 0,16647 & 0,898511 & 0,23346 & 0,509470 & 0,26547 \\
\hline México & 0,447398 & 0,27967 & 0,365734 & 0,34686 & 0,260890 & 0,76433 \\
\hline Chile * & 0,002645 & 0,26552 & 0,730402 & 0,19288 & 0,747116 & 0,20274 \\
\hline Tailândia & 0,350065 & 0,16796 & 0,910556 & 0,31546 & 1,217191 & 0,47219 \\
\hline EUA & 0,769715 & 0,22816 & 0,810639 & 0,65587 & 0,845640 & 1,00908 \\
\hline Inglaterra & 0,455987 & 0,60934 & 1,214430 & 0,52030 & 1,361411 & 0,37342 \\
\hline Alemanha & 0,726739 & 0,76145 & 1,159962 & 1,03583 & 1,475865 & 1,12862 \\
\hline França & 0,396969 & 0,29214 & 1,043104 & 0,91158 & 1,060298 & 1,08570 \\
\hline Itália & 0,940274 & 0,51075 & 0,894443 & 0,64516 & 0,985193 & 0,92196 \\
\hline Espanha & 0,911388 & 0,33024 & 1,109343 & 0,59621 & 1,198020 & 0,64161 \\
\hline Bélgica & 0,389658 & 0,73849 & 0,728294 & 0,56753 & 1,288004 & 0,51314 \\
\hline Canadá & 0,496351 & 0,72473 & 0,823095 & 0,65001 & 0,863382 & 0,81997 \\
\hline Holanda & 0,496044 & 0,33659 & 1,074956 & 0,41146 & 1,541388 & 0,84480 \\
\hline Suécia & 0,861347 & 0,48669 & 1,454842 & 0,73316 & 1,096173 & 0,71048 \\
\hline Venezuela & 0,295645 & 0,51685 & 0,373926 & 0,76917 & 0,143171 & 0,96311 \\
\hline África do Sul & 0,629186 & 0,51616 & 0,556105 & 0,49005 & 0,764455 & 0,39404 \\
\hline
\end{tabular}


Tabela 1.1_ Indicadores Crédito/PIB e Depósitos/PIB dos países estudados nos anos 1971, 1990 e 2000

\begin{tabular}{|c|c|c|c|c|c|c|}
\hline \multirow{2}{*}{ Países } & \multicolumn{2}{|c|}{1971} & \multicolumn{2}{|c|}{1990} & \multicolumn{2}{|c|}{2000} \\
\hline & Crédito/PIB & Depósitos/PIB & Crédito/PIB & Depósitos/PIB & Crédito/PIB & Depósitos/PIB \\
\hline Peru & 0,274962 & 0,28415 & 0,202094 & 0,35794 & 0,264356 & 0,16480 \\
\hline Japão & 0,935924 & 0,57209 & 1,377120 & 0,50587 & 1,417192 & 0,54356 \\
\hline Irlanda & 0,473287 & 0,17095 & 0,551787 & 0,16645 & 1,084730 & 0,26115 \\
\hline Grécia & 0,360279 & 0,54614 & 1,006460 & 0,38740 & 1,024059 & 0,79315 \\
\hline Portugal & 0,690594 & 0,29125 & 0,717514 & 0,63077 & 1,429423 & 0,57339 \\
\hline Austrália & 0,410828 & 0,77475 & 0,722083 & 0,75857 & 0,941390 & 0,99654 \\
\hline Dinamarca** & 0,469106 & 0,39702 & 0,630159 & 0,51923 & 0,531588 & 0,64108 \\
\hline Noruega & 0,491004 & 0,26622 & 0,674323 & 0,54295 & 0,444765 & 0,48362 \\
\hline Coréia do Sul & 0,366972 & 0,38049 & 0,571564 & 0,55466 & 0,927168 & 0,48474 \\
\hline Indonésia & 0,140795 & 0,11990 & 0,454782 & 0,35722 & 0,662228 & $0,51364$. \\
\hline
\end{tabular}

Fonte: International Financial Statistics Yearbook 1971, 1990 e 2000.

Notas: $(*)$ Dados de 1979 .

(**) Em 2000, dados de 1999. 
Anexo B

Ordenamento dos países por classes

Tabela 2.1_Classificação dos países por classes de crédito/PIB nos anos de 1971, 1990 e 2000

\begin{tabular}{|c|c|c|c|c|c|c|}
\hline Classes & 19 & & 19 & & & \\
\hline 1 & $\begin{array}{l}\text { Chile } \\
\text { Indonésia } \\
\text { Peru } \\
\text { Venezuela }\end{array}$ & $\begin{array}{l}(0,0053) \\
(0,2819) \\
(0,5505) \\
(0,5919)\end{array}$ & $\begin{array}{l}\text { Peru } \\
\text { Argentina } \\
\text { México } \\
\text { Venezuela } \\
\text { Indonésia }\end{array}$ & $\begin{array}{l}(0,2552) \\
(0,4094) \\
(0,4619) \\
(0,4722) \\
(0,5743)\end{array}$ & $\begin{array}{l}\text { Venezuela } \\
\text { México } \\
\text { Peru } \\
\text { Argentina } \\
\text { Noruega } \\
\text { Brasil } \\
\text { Dinamarca }\end{array}$ & $\begin{array}{l}(0,1582) \\
(0,2884) \\
(0,2922) \\
(0,3795) \\
(0,4916) \\
(0,5631) \\
(0,5876)\end{array}$ \\
\hline 2 & $\begin{array}{l}\text { Argentina } \\
\text { Tailândia } \\
\text { Grécia } \\
\text { Coréia do Sul } \\
\text { Brasil } \\
\text { Bélgica } \\
\text { França } \\
\text { Austrália } \\
\text { México } \\
\text { Reino Unido } \\
\text { Dinamarca } \\
\text { Irlanda } \\
\text { Noruega } \\
\text { Holanda } \\
\text { Canadá }\end{array}$ & $\begin{array}{l}(0,6314) \\
(0,7009) \\
(0,7213) \\
(0,7347) \\
(0,7751) \\
(0,7801) \\
(0,7948) \\
(0,8225) \\
(0,8957) \\
(0,9129) \\
(0,9392) \\
(0,9476) \\
(0,9830) \\
(0,9931) \\
(0,9936)\end{array}$ & $\begin{array}{l}\text { Irlanda } \\
\text { África do Sul } \\
\text { Coréia do Sul } \\
\text { Dinamarca } \\
\text { Noruega } \\
\text { Portugal } \\
\text { Austrália } \\
\text { Bélgica } \\
\text { Chile }\end{array}$ & $\begin{array}{l}(0,6968) \\
(0,7023) \\
(0,7218) \\
(0,7958) \\
(0,8516) \\
(0,9061) \\
(0,9119) \\
(0,9197) \\
(0,9224)\end{array}$ & $\begin{array}{l}\text { Indonésia } \\
\text { Chile } \\
\text { África do Sul } \\
\text { EUA } \\
\text { Canadá }\end{array}$ & $\begin{array}{l}(0,7320) \\
(0,8258) \\
(0,8449) \\
(0,9347) \\
(0,9543)\end{array}$ \\
\hline
\end{tabular}


Tabela 2.1_Classificação dos países por classes de crédito/PIB nos anos de 1971, 1990 e 2000

\begin{tabular}{|c|c|c|c|c|c|c|}
\hline Classes & & & 19 & & 2000 & Iconclu \\
\hline \multirow[t]{9}{*}{3} & África do Sul & $(1,2597)$ & EUA & $(1,0237)$ & Coréia do Sul & $(1,0248)$ \\
\hline & Portugal & $(1,3827)$ & Canadá & $(1,0394)$ & Austrália & $(1,0405)$ \\
\hline & & & Itália & $(1,1295)$ & Itália & $(1,0889)$ \\
\hline & & & Brasil & $(1,1347)$ & Grécia & $(1,1319)$ \\
\hline & & & Tailândia & $(1,1499)$ & França & $(1,1719)$ \\
\hline & & & Grécia & $(1,2710)$ & Irlanda & $(1,1989)$ \\
\hline & & & França & $(1,3173)$ & Suécia & $(1,2116)$ \\
\hline & & & Holanda & $(1,3575)$ & Espanha & $(1,3242)$ \\
\hline & & & Espanha & $(1,4009)$ & Tailândia & $(1,3454)$ \\
\hline \multirow[t]{6}{*}{4} & Alemanha & $(1,4550)$ & Alemanha & $(1,4648)$ & Bélgica & $(1,4236)$ \\
\hline & EUA & $(1,5411)$ & Reino Unido & $(1,5336)$ & Reino Unido & $(1,5048)$ \\
\hline & Suécia & $(1,7245)$ & Japão & $(1,7391)$ & Japão & $(1,5664)$ \\
\hline & Espanha & $(1,8247)$ & Suécia & $(1,8372)$ & Portugal & $(1,5799)$ \\
\hline & Japão & $(1,8738)$ & & & Alemanha & $(1,6313)$ \\
\hline & Itália & $(1,8825)$ & & & Holanda & $(1,7037)$ \\
\hline
\end{tabular}

Fonte: International Financial Statistics Yearbook 1971, 1990 e 2000

Nota: Os valores constantes na tabela acima são referentes à média do conjunto desses 27 países considerada igual a 1,00 . 
Tabela 2.2_Classificação dos países por classes de depósitos/PIB nos anos 1971, 1990 e 2000

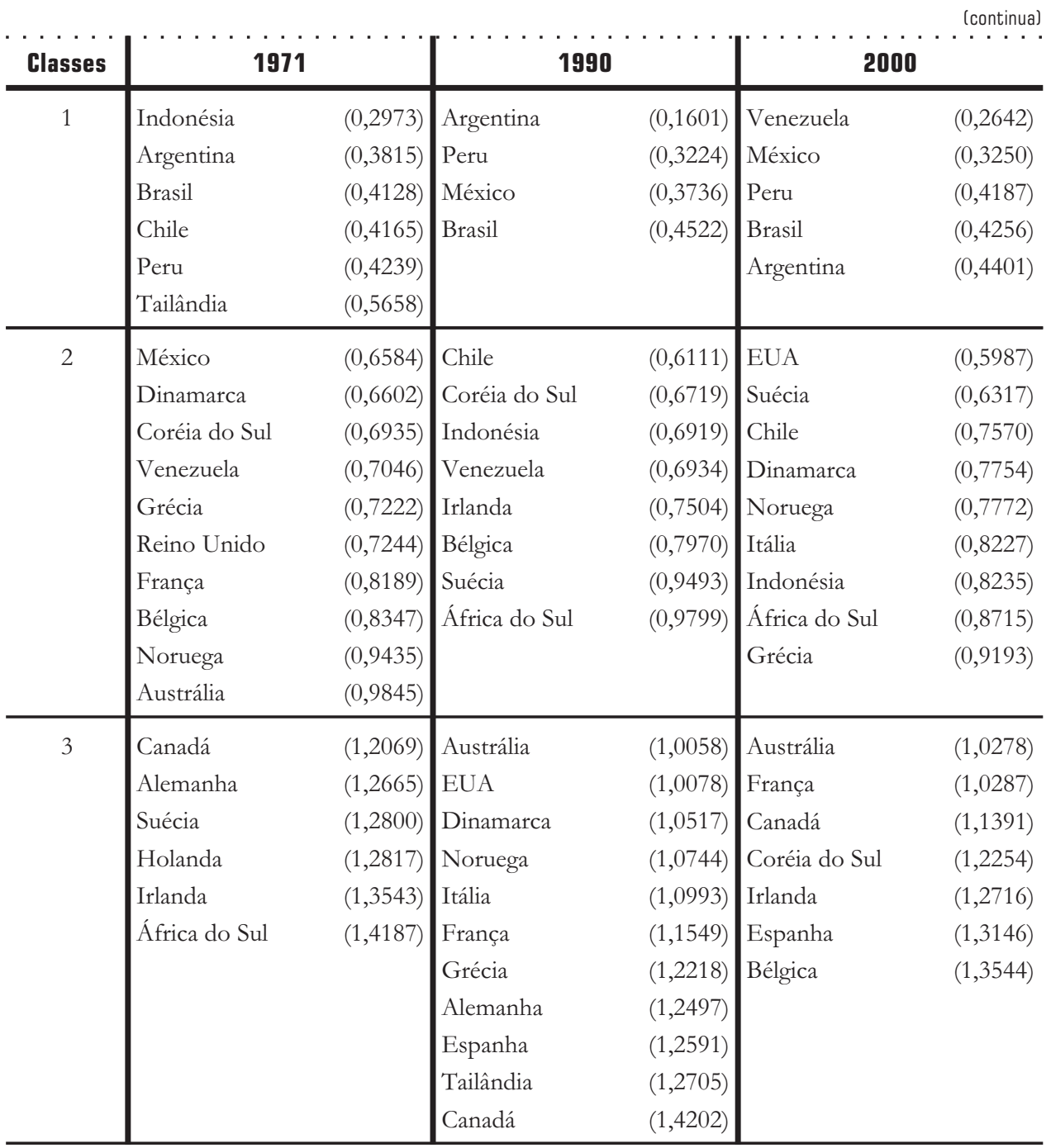


Tabela 2.2_Classificação dos países por classes de depósitos/PIB nos anos 1971, 1990 e 2000

\begin{tabular}{|c|c|c|c|c|c|c|}
\hline Classes & & & & & 20 & Iconclu \\
\hline \multirow[t]{5}{*}{4} & EUA & $(1,5110)$ & Portugal & $(1,4694)$ & Alemanha & $(1,4781)$ \\
\hline & Espanha & $(1,7972)$ & Holanda & $(1,4899)$ & Holanda & $(1,5441)$ \\
\hline & Itália & $(1,8313)$ & Reino Unido & $(1,7658)$ & Portugal & $(1,5977)$ \\
\hline & Japão & $(1,8882)$ & Japão & $(2,0065)$ & Tailândia & $(1,6178)$ \\
\hline & Portugal & $(1,9212)$ & & & $\begin{array}{l}\text { Reino Unido } \\
\text { Japão }\end{array}$ & $\begin{array}{l}(1,7407) \\
(1,8095)\end{array}$ \\
\hline
\end{tabular}

Fonte: International Financial Statistics Yearbook 1971, 1990 e 2000.

Nota: Os valores constantes na tabela acima são referentes à média do conjunto desses 27 países considerada igual a 1,00 
Anexo C

\section{Equações de diferença \\ e matrizes de transição}

Conforme visto na página 174, foram estabelecidas quatro classes de níveis de crédito/PIB:

1. valores abaixo de 0,5982;

2. valores entre 0,5982 e 1,00;

3. valores acima de 1,00 até 1,4018;

4. valores acima de 1,4018.

Esses valores são relativos à média dos países considerada igual a 1,00. Também foram estabelecidas quatro classes de níveis de depósitos/PIB, sendo os valores relativos à média dos países. As classes obtidas foram:

1. valores abaixo de 0,5798 ;

2. valores entre 0,5798 e 1,00;

3. valores acima de 1,00 até 1,4202;

4. valores acima de 1,4202.
No sistema de equações de diferenças, considera-se $F_{t}$ como a distribuição dos países no tempo $t, M$ a matriz de transição de Markov, indicando a probabilidade de cada país na classe $i$ no tempo $t$ estar na classe $j$ no tempo $t+1$ e $F_{t+1}$ a distribuição dos países no tempo $t+1$. Assim, o sistema de equações, que expressa a evolução da distribuição ao longo do tempo, pode ser representado por: $F_{t+1}=M F_{t}$.

Abaixo constam os sistemas de equações de diferenças referentes ao crédito/PIB e depósitos/PIB e aos períodos de 1971 a 1990 e de 1990 a 2000, com as respectivas matrizes de transição ou de Markov.

\section{Figura 1_ Sistema de equações de diferenças referente ao crédito/PIB} e o período base de 1971 a 1990

$\left[\begin{array}{l}F 1_{t+1} \\ F 2_{t+1} \\ F 3_{t+1} \\ F 4_{t+1}\end{array}\right]=\left[\begin{array}{cccc}0,75 & 0,133 & 0 & 0 \\ 0,25 & 0,400 & 1,00 & 0 \\ 0 & 0,400 & 0 & 0,50 \\ 0 & 0,067 & 0 & 0,50\end{array}\right]\left[\begin{array}{l}F 1_{t} \\ F 2_{t} \\ F 3_{t} \\ F 4_{t}\end{array}\right]$


Figura 2_Sistema de equações de diferenças referente ao crédito/PIB e o período base de 1990 a 2000

$$
\left[\begin{array}{l}
F 1_{t+1} \\
F 2_{t+1} \\
F 3_{t+1} \\
F 4_{t+1}
\end{array}\right]=\left[\begin{array}{cccc}
0,80 & 0,222 & 0,111 & 0 \\
0,20 & 0,222 & 0,222 & 0 \\
0 & 0,334 & 0,556 & 0,25 \\
0 & 0,222 & 0,111 & 0,75
\end{array}\right]\left[\begin{array}{l}
F 1_{t} \\
F 2_{t} \\
F 3_{t} \\
F 4_{t}
\end{array}\right]
$$

Figura 3_ Sistema de equações de diferenças referente aos depósitos/PIB e o período base de 1971 a 1990

$$
\left[\begin{array}{l}
F 1_{t+1} \\
F 2_{t+1} \\
F 3_{t+1} \\
F 4_{t+1}
\end{array}\right]=\left[\begin{array}{cccc}
0,500 & 0,10 & 0 & 0 \\
0,333 & 0,30 & 0,500 & 0 \\
0,167 & 0,50 & 0,333 & 0,60 \\
0 & 0,10 & 0,167 & 0,40
\end{array}\right]\left[\begin{array}{l}
F 1_{t} \\
F 2_{t} \\
F 3_{t} \\
F 4_{t}
\end{array}\right]
$$

Figura 4_Sistema de equações de diferenças referente aos depósitos/PIB e o período base de 1990 a 2000

$$
\left[\begin{array}{l}
F 1_{t+1} \\
F 2_{t+1} \\
F 3_{t+1} \\
F 4_{t+1}
\end{array}\right]=\left[\begin{array}{cccc}
1,00 & 0,125 & 0 & 0 \\
0 & 0,500 & 0,454 & 0 \\
0 & 0,375 & 0,364 & 0 \\
0 & 0 & 0,182 & 1,00
\end{array}\right]\left[\begin{array}{l}
F 1_{t} \\
F 2_{t} \\
F 3_{t} \\
F 4_{t}
\end{array}\right]
$$

